\title{
Introduction to the Special Issue Call for Qualitative Research Tutorials in Contemporary Administration Studies: An Editorial
}

\author{
Introdução à Chamada de Artigos Tutoriais de Pesquisa Qualitativa em \\ Estudos de Administração Contemporânea para Edição Especial da RAC: \\ Um Editorial
}

Evelyn Lanka*1ఠ Ali Rostron ${ }^{2}$ Pallavi Singh ${ }^{3}$ ( Sanjay Lanka ${ }^{4}$

\section{INTRODUCTION}

In the editorial for our special issue call, we outlined our perspective of qualitative research and the need to address the teaching of qualitative methods to help foster more rigorous application of qualitative research in contemporary administration and management studies (Lanka, Lanka, Rostron, \& Singh, 2021). Our call for tutorial papers in RAC (Revista de Administração Contemporânea) (Lanka, Lanka, Rostron, \& Singh, 2019) was the mechanism through which we aimed to promote awareness, understanding, and learning of how to properly and effectively apply qualitative research methods for administration and management researchers. This current editorial aims to position our special issue as well as present our thoughts on important and pressing issues related to qualitative research in contemporary administration and management studies. We believe these issues are critical to the future of qualitative research in our field. We will also present the papers that were accepted to the special issue and outline how each one promotes understanding of qualitative research methods.

\footnotetext{
* Corresponding Author.

1. Cranfield University, Cranfield School of Management, Cranfield, United Kingdom.

2. University of Liverpool, Liverpool, United Kingdom.

3. Sheffield Hallam University, Sheffield, United Kingdom.

4. Fundação Getulio Vargas, Escola de Administração de Empresas de São Paulo, São Paulo, SP, Brazil.
}

\section{KEY ISSUES IN QUALITATIVE RESEARCH METHODS IN MANAGEMENT STUDIES}

The challenges of generalization, validity, and reliability in qualitative research

For those who move their analytical focus from quantitative to qualitative research, there is often the question of how to evaluate the rigor of qualitative research. Many novice researchers may feel pressured to prove that their qualitative research findings are 'valid' or represent a 'true reality' (Hamilton, 2020). This issue brings up a significant challenge facing qualitative research from the view of nomothetic research (read quantitative) critics, which is that many quantitative researchers view qualitative research as being incapable of generalizability and therefore not valid (Maxwell, 2021). It is certainly the case that many qualitative scholars would argue that there is no need to assess qualitative research through the lens of quantitative standards. This argument is based upon understanding the

Cite as: Lanka, E., Rostron, A., Singh, P., \& Lanka, S. (2022). Introduction to the special issue call for qualitative research tutorials in contemporary administration studies: An editorial. Revista de Administração Contemporânea, 26(4), e210333. https://doi.org/10.1590/1982-7849rac2022210333.en 
differences between the ontological and epistemological underpinnings of qualitative and quantitative research.

However, it is still the case that the generalizability of research is often held as a mark of its rigor, with this perspective of course coming from the view that there is only one measurable and objective reality (Hamilton, 2020). Therefore, from this perspective, if something is found to be true in one situation, it should hold true across all others, because they are equally representative of the single definable reality. However, what it means to generalize, and what generalizability is, are often not clearly understood (Maxwell, 2021). This lack of accurate and clear definitions of how generalization might be assessed and whether it applies to only nomothetic or might also apply to idiographic (qualitative) research needs to be addressed.

To this end, Firestone (1993) offers some promising insights. He proposed that there are three forms of generalizability with which researchers should be concerned. They are: (a) extrapolation from sample to population, (b) analytic generalization or extrapolation using a theory, and (c) case-to-case translation (as cited by Varpio et al., 2021). The first example of generalizability, (a), refers to statistical generalization. That is, the findings are derived from a large sample that is thought to be statistically representative. Findings are therefore thought to be statistically applicable to all members of said population. This is most often the form of generalization from which quantitative researchers attempt to assess qualitative research, likely due to their lack of understanding of other forms of generalization. However, it should be made clear that generalizing from statistics is neither necessary nor desirable from the ontological perspective of qualitative research.

The second argument, (b), is analytic or theoretical generalizability, as outlined by Varpio et al. (2021). From this perspective, the researcher aims to evaluate local findings through the development of new theories or to validate existing theories. Varpio et al. (2021) write that in "this approach to generalisability, researchers engage in inductive, in-depth data analysis to generate higherorder abstractions relevant to many of their research participants. These theories or concepts being developed by the research effort are the outcomes that are generalisable" (Varpio et al., 2021, p. 170). Critically, although this form of generalization is the most relevant to qualitative researchers, they seldom use this language, perhaps for fear of being accused of pandering to the 'quants.' This view of conceptual or theoretical generalizability is deeply grounded in the concept of ecological validity. Ecological validity refers to the validation of one's research findings in relationship to the context from which they were gathered (Schmuckler, 2001). In other words, how closely the findings represent and illuminate the lived experience of the research participants.

Firestone (1993) also outlines a third approach, (c), as naturalistic generalizability. From this approach, the researcher is concerned with understanding or describing how a person in one setting considers adopting a program or idea from another one. This is similar to Guba and Lincoln (1989) concept of transferability. As Firestone (1993) and Varpio et al. (2021) both outline, qualitative researchers - those approaching their research from a social constructionist and/or inductive approach - can aim for theoretical generalizability (approach b) and/or naturalistic generalizability (approach c), if they choose to engage with the concept of generalizability.

However, addressing the issue of generalizability is not the only pressing issue for qualitative researchers (Hamilton, 2020). There is the ongoing concern of addressing and controlling for researcher bias and ensuring the reliability and validity of qualitative research (Guba \& Lincoln, 1989; Kirk \& Miller, 1986; Maxwell, 1992). While it is clearly necessary to evaluate research and ensure that clearly biased research motivated by racism, sexism, and so on does not make its way into the discourse, assuming that qualitative methods are more susceptible to these issues in comparison to quantitative research methods is shortsighted (Golafshani, 2003). It is important to understand that both qualitative and quantitative research can be influenced by researcher bias, in how and what data is collected, how it is interpreted, and how and where it is disseminated.

Rather than attempting to control all bias, it might be more useful to acknowledge its inevitable existence and our role as researchers, who will always be biased, and how this might affect our research (Golafshani, 2003; Maxwell, 1992; Maxwell, 2021). Many qualitative researchers build into their research practices means for acknowledging and reflecting upon the role of bias in the research process. This process, which is known as reflexivity, is a fruitful means through which all researchers can gain greater understanding of how their role in the process of knowledge generation might shape how they interpret and make sense of the stories told to them by their participants (Braun \& Clarke, 2019). For those qualitative researchers who practice reflexivity, many find it useful to keep a reflexivity journal as part of their data analysis and collection process. In this practice, the researchers would document their activities as they move through the research process, reflecting, critiquing, and analyzing their own thoughts, emotions, and insights regarding the research project (Finlay, 2002; Macbeth, 2001; Shaw, 2010; Watt, 2007). However, reflexivity is not simply a means through which to draw lines around our own preconceived notions about our research (Berger, 2015; Bott, 2010; Skeggs, 2002). Mauthner and Doucet (2003) 
argue that reflexivity is also important when researching and writing about the lives of others, because it forces the researchers to be explicit about their role in presenting data that effectively comes from the lives and experiences of others, therefore giving space to the researchers to outline how and why they interpreted their data in the way they did. As Braun and Clarke (2019) outline, the subjectivity of the researcher should be seen as a resource rather than a liability in the qualitative process.

Furthermore, regarding validity and reliability in qualitative research, it may be useful to understand what has been proposed for evaluating the trustworthiness of qualitative research. Guba (1981) and Guba and Lincoln (1989) state that there are four major concerns for evaluating the trustworthiness of qualitative data. These are: truth value, applicability, consistency, and neutrality (Guba, 1981). Truth value is the concept of how one can establish confidence in the truth of qualitative findings (Guba, 1981). Applicability is concerned with the degree to which the findings can be applied in other settings or contexts (Guba, 1981). Consistency deals with whether the findings can consistently be repeated in the same context (Guba, 1981). Finally, neutrality deals with how to "establish the degree to which the findings have been generated by the study participants and not as a result of the biases, motivations, interests, perspectives, and so on of the researcher" (Guba, 1981, p. 80). These guidelines are again provided for researchers who might need to engage with these concepts in their research process or for those who might find these concepts useful for engaging with a specific audience. However, it is still the case that many qualitative researchers may not find it useful or necessary to engage with quantitative discourses around validating and documenting reliability. This position should not be interpreted as a lack of academic rigor. Rather, we again point the reader to the underlying ontological and epistemological underpinnings of qualitative research, which address reliability and validity differently from quantitative research. If readers would like to review these issues, they might find Lanka, Lanka, Rostron, and Singh (2021) useful to read. Our motivation for outlining these different views is to present both sides of this argument in order to engage different audiences with different needs and approaches with regard to how they conduct qualitative research. In this regard, we find it useful to next address what questions qualitative research allows us to ask.

\section{What are the questions that qualitative research allows us to ask?}

The discourse around 'what questions does qualitative research help uncover?' is typically rooted in the definition and fundamental concepts of qualitative inquiry. As Denzin and Lincoln (2011) define:

"Qualitative research is a situated activity that locates the observer in the world. This means that qualitative researchers study things in their natural settings, attempting to make sense of, or interpret, phenomena in terms of the meanings people bring to them" (Denzin \& Lincoln, 2011, p. 3).

The base of qualitative research inquiry is that it aims to address the meaning individuals or groups ascribe to a social or human problem (Creswell, 2012) and it places social interaction and social processes at the center of this approach (Strauss, 1987). Therefore, the qualitative research question needs to articulate what a researcher wants to know about the intentions and perspectives of those involved in the social interaction and places viewpoints of the actors in the phenomenon at the center stage. It involves asking questions on the how and why of human interactions and generally leads to the answers that describe, explain, or outline the story of a social process.

Different to quantitative studies, a qualitative inquiry does not begin with a hypothesis but also cannot begin without a plan (Richards, 2005). The researchers do need some initial questions; even those who use grounded theory begin with broader questions after entering the potential research site (Agee, 2009). Good questions can grow out of initial curiosity or ideas and can start with the likes of 'what do I want to know in the study?' (Janesick, 2000). Charmaz (2006) suggests that broad questions such as 'what's going on here?', 'what are the basic social processes?', and 'what are the basic social psychological processes?' can serve to help a researcher find some initial focus. Marshall and Rossman (2014) describe questions that perform four different functions: exploratory, explanatory, descriptive, and emancipatory. Maxwell (2012) called these early questions 'provisional' because contrary to the quantitative inquiry, the qualitative research questions are not stagnant and confirmed at the beginning of the research project. The questions change during the process of research to reflect an increased understanding of the problem, and are 'evolving' (Creswell, 2007).

Qualitative question development is a continuous process and is usually developed or refined at all stages of the project. Agee (2009) calls development of qualitative research questions "a reflexive and interactive inquiry journey." First iterations of questions are tentative and exploratory but give researchers a tool for articulating the primary focus of the study. Qualitative questions should invite a process of exploration and discovery and should not become trapped in the motive of being 'focused' in the initial stages. Starting with overly focused questions can lead to tunnel vision and can inhibit a researcher's understanding and analysis 
(Maxwell, 2012). Creating discovery-oriented questions can help a researcher use the process of developing and refining questions as a basis for a more rigorous and reflexive inquiry (Agee, 2009). The iterative process of qualitative research question development relies on the researchers' capacity to examine their own role and perspective in the process and also how they have positioned themselves in relation to the participants. Therefore, qualitative research inquiry has gradually moved toward involving participants in the process of question development (Flick, 2018; Maxwell, 2012), especially in the participatory action research, which requires all stakeholders whose lives are affected by the problem under study to be engaged in the process of investigation (Stringer, 2007).

Qualitative studies can reveal how people experience and think about events and social relations (Flick, 2018). The researcher is representing the lives of individuals, and the kinds of question a researcher asks become paramount when considering the short- and long-term effects on others. Developing qualitative research questions should include careful thought about how the direction of the inquiry will position the researcher in relation to participants and what the implications will be for the participants' lives. This ethical aspect of the question should be an integral part of conceptualization and a continuous reflective process in the development of the qualitative research question.

\section{Addressing diverse voices in qualitative research}

In addition to the questions that are asked through qualitative research, there is also the need to understand how research participants are considered and engaged with. There is a recognized need to address the spectrum of voices and experiences of individuals through qualitative research. Contemporary administration research is not immune to this need, and in fact has struggled to reflect, through its research and training, the diversity of perspectives. In this regard, we believe that addressing emancipatory and decolonial research is one way to account for the diversity of perspectives in qualitative research. This approach does not simply ask qualitative researchers to capture a greater depth of research topics or participants, but rather challenges researchers to address critical challenges that have silenced or obscured certain voices.

In this context, we would like to bring attention to the need to use qualitative research to bring out the perspective of the subaltern, who we define as a member of society whose perspective has not only been repressed but whose needs have been ignored by both the business community and those in political power. We therefore call for qualitative research that questions the focus on the perspectives of the elites, corporations, and their management. Real emancipatory change will require that those whose lives are impacted by the actions of the corporate-state nexus are given a voice. Consistent with Cooper and Sherer (1984), we call for management, accounting, and finance research that "... involves the adoption of a more emancipated view of human motivation ... a view that acknowledges the potential of people (and accounting) to change and reflect differing interests and concerns" (Cooper \& Sherer, 1984, p. 219). This would represent research that brings attention to the policies of government and the structures of corporate governance in perpetuating "poverty, social inequality and inequitable distribution of wealth" (Sikka, Wearing, \& Nayak, 1999, p. 5). We propose a fundamental change in the way academics engage with the broader community by taking on a more critical and questioning stance, in a manner that makes it more accessible and makes clear the role played by historical and political forces (Willmott, Puxty, \& Sikka, 1993) in perpetuating inequalities.

We see the need for greater focus on qualitative research since the status quo is perpetuated by a quantitative approach whose ontology and epistemology fail to ask the 'why' question regarding these inequalities. Leadership, accounting, and finance are examples of areas in contemporary administration and management research that have maintained a firm grip on the use of quantitative methods and prolonged the status quo. Qualitative research in leadership studies, for example, allows researchers to address the more subjective and socially constructed nature of leadership and followership (Lanka, Topakas, \& Patterson, 2020). In this way, the goal of qualitative research should be to bring forward, give space to, and advocate for the stories of those whose voice has been silenced.

This is especially critical for addressing key issues such as the impacts of climate change and the COVID-19 pandemic, which have increased inequalities and shown the lack of accountability of both the corporate sector and the government. The loss of access to basic education, food sovereignty, and employment, especially for women, brings out the need for greater intersectionality in research to understand and remedy the challenges faced by sustainable development. There is therefore a need to emphasize the perspective of the subaltern and question many of the taken-for-granted assumptions, especially regarding the food system and agriculture. Lanka, Khadaroo, and Böhm (2017) provide an account of the subaltern, bringing out the role of biodiversity and ecosystem services in ensuring the livelihoods of a cooperative of indigenous smallholder farmers. This brings up the fact that we have socio-ecological systems so that when we consider the environmental impact, we must also consider the related social impact, especially on the less powerful stakeholder groups impacted by MNCs. 
This will require a qualitative approach, giving voice to their perspective.

\section{Qualitative research - A living, lively field}

The five papers selected for this special issue each make their own important contribution toward both our aims of promoting the value of qualitative research within contemporary administration and management research and providing guidance for effectively conducting such research. We summarize each paper in the second half of this editorial. However, the five papers also speak to and reflect some wider trends within the field of qualitative research methods, which we wish to also highlight. The three themes we elaborate on below all support our contention that qualitative research should not be approached or compared with the paradigms and quality measures of quantitative methods, but recognized as a living, lively, and innovative field in its own right.

The first theme reflected by the papers is a concern with extending methods. Traditionally, qualitative research within contemporary administration and management studies has been dominated by the interview method (Holstein \& Gubrium, 2011) and, with this in mind, we include a paper by Cheron, Salvagni, and Colomby (2022) that addresses this method in detail. Qualitative interviews can be an entirely appropriate method: if you want to know what people think about a phenomenon, what better way than to ask them and listen to what they have to say about their experience and perspectives of it? (Cheron, Salvagni, \& Colomby, 2022; Van Manen, 1997; Watson, 1998). Nevertheless, Silverman (2006) warns against it becoming method by default, and qualitative research projects within management studies have increasingly started to reflect a willingness to apply, and to devise, innovative methods with which to investigate and to 'get at' organizational phenomena such as the elicitation or collection of visual data (Bell, Warren, \& Schroeder, 2014) and stories (Gabriel \& Griffiths, 2004; Riessman, 2008). Our selected papers also reflect such willingness. Deus, Campos, and Rocha (2022) present a new method of collecting and then analyzing the recent social phenomenon of memes as a way of gaining alternative and original insights into cultural discourses. The papers by Behling, Lenzi, and Rossetto (2022) and Silva, Sauerbronn, and Thiollent (2022) explore how qualitative methods of interactive qualitative analysis (IQA) and participatory action research (PAR), used more commonly in other fields, might be applied to management, organization, and administrative studies; and Melo and Dourado (2022) offer a comprehensive review that scopes the range and nature of possible qualitative methods for investigating online social phenomena and interactions.
The second theme is responding to emergent forms of social and organizational life. As "an emergent, inductive, interpretive and naturalistic approach to the study of people, cases, phenomena, social situations and processes in their natural settings in order to reveal in descriptive terms the meanings that people attach to their experiences of the world" (Yilmaz, 2013, p. 312), qualitative research remains an essential way of investigating such natural settings, and especially as such settings evolve and change. Qualitative research therefore needs to remain alert to emerging forms of social life and phenomena and be able to design and adapt methods to enable us to 'get at' - to appropriately investigate and reflect - such forms. This concern with discerning and reflecting new and different forms of social life also helps clarify an important complementary role for qualitative research in uncovering, exploring, and mapping out areas of social life that might then be further examined, including being quantified and measured.

One such area is how social life and social interactions are emerging and evolving within the online sphere. While Deus et al. (2022) examine one particular new form in detail - that of memes as new cultural texts, Melo and Dourado (2022) seek to discern and elaborate the particular nature of online social interactions and their implications for designing appropriate qualitative methods to examine them. Another area is a concern with social justice, and particularly how subaltern voices and experiences can not only be recognized and heard, but also enabled to challenge dominant voices, practices, and epistemologies. In their paper, Silva et al. (2022) explicitly link the decolonial agenda to practices of research itself and the imposition and reproduction of colonial hegemonies through management, accounting, and research practices. They argue that 'non-extractive methods' such as participatory action research offer a means by which research can include participants not simply as subjects or contributors but as co-constructors of knowledge; a theme also highlighted by Cheron et al. (2022), who observe how interviews 'reframe' participants in the research process from 'mere sources of information' to co-producers of knowledge based on a shared interest in the phenomenon under study. However, Silva et al. (2022) also discuss how such methods also challenge researcher 'blind spots' arising from their own interests or 'grand theories,' by addressing the local experience of participants and producing knowledge that is useful in that local context. This concern with the local experience and knowledge of participants, and the critique of the allknowing, all-seeing researcher is also reflected in Behling et al. (2022). The method of interactive qualitative analysis seeks not to create theory to explain participant experience, but to uncover 'theories in action' that inform and guide how a group makes sense of a particular phenomenon, and thus can also help challenge the status quo supported by existing theories in any given area of knowledge. Similarly, 
Melo and Dourado (2022)also reflect on how the nature of online social interactions might also encourage more collaborative forms of research. They note in particular how the online sphere supports the democratization of research practices by blurring certain boundaries between researcher and researched, for example because the researched are now also able to research the researchers' online profile and their digital and social media footprint, and because both parties meet and converse in a shared online space.

The third theme concerns how qualitative methods can generate new possibilities for researching management and organizations. The five papers not only propose how qualitative methods can generate new management and organizational knowledge that enables us to know and understand something better, but how such methods also open up possible new ways of seeing, getting at, and thinking about contemporary administration and management itself; that is the epistemology of administration and management research. This theme is by no means a feature of all qualitative research, and nor is it true that quantitative research is not capable of being highly innovative. Nevertheless, this feature of qualitative research, and its capacity to challenge how we might know contemporary administration and management and what there might be to know, can be seen as a reflection both of the difficulties and challenges of justifying qualitative research methods and demonstrating their validity and value and of their often exploratory nature.

Our selected papers pose, and try to answer, a number of questions concerning the epistemologies and practices underpinning this research. One common question is how we might know better. All the papers are concerned, to some extent, with widening perspectives of any management, organizational, or social phenomenon: by seeking out and including subaltern voices (Melo \& Dourado, 2022; Silva, Sauerbronn, \& Thiollent, 2022) and marginalized ideologies (Deus, Campos, \& Rocha, 2022), developing dialogues and collaborative approaches with research participants (Cheron et al., 2022; Melo \& Dourado, 2022; Silva et al., 2022), uncovering and surfacing endogenous theories in use by participants themselves (Silva et al., 2022), reflecting multiple and diverse perspectives (Deus et al., 2022), or capturing and tracking social attitudes over time (Deus et al., 2022). A second question is what we might study better, or how we might expand topics of interest and relevance for management and organization studies. Silva et al. (2022), for example, argue that by taking a decolonial, non-extractive, and participatory approach, research into accounting can extend beyond 'control of profitability for shareholders' (Silva et al., 2022) into various forms of societal concerns and demands, such as environmental impact, gender and racial violence, and human rights. Melo and Dourado (2022) argue that the process of working out how best to research 'online as a full form of human life' also leads to developing new insights into the full nature of that form of life, and to knowing the world in ways that cannot currently be envisaged.

\section{INTRODUCTION TO THE SPECIAL ISSUE}

\section{Memes as Shortcut to Consumer Culture: A Methodological Approach to Covert Collective Ideologies}

This paper by Deus et al. (2022) proposes the methodological use of memes as a shortcut to explore consumer culture. The authors argue that memes as cultural texts can reveal collective circulating ideologies that may not be accessed through regular interviews. Memes are cultural texts that convey easy-to-understand messages, gaining strength within social networks. Cultural texts playfully present the social context and beliefs of societies. In this paper, the authors analyzed circulating memes during the COVID-19 pandemic about elderly consumers in Brazil to outline a methodological protocol. Their method of analysis was to gather and code memes adopting the discourse model to conduct qualitative research of memes as a shortcut to cultural discourses. They collected memes between March and May 2020 using social media networks. They then coded and analyzed their data using thematic analysis. This process of analysis began with the outline of a data collection protocol, followed by data analysis guidelines, illustrated by the context of elderly consumers. The analysis of memes as cultural texts contributed to understanding of consumer behavior through current cultural content, revealing contrasting ideologies that emerge from consumers, as uncovered value-systems, circulating alongside institutional mass-mediated ideologies. The value of this paper in terms of how it addresses qualitative methods is that it allows the reader to understand how to apply a popular qualitative method (thematic analysis) to social media. In this way, we believe that this paper makes a significant contribution to teaching both methods, as well as how to fruitfully apply methods to a challenging and dynamic topic such as social media.

\section{Clues for the Paradigmatic Development of Online Qualitative Methods}

This paper by Melo and Dourado (2022) discusses how the idiosyncratic properties of the online context might drive the development of future online qualitative methods. The authors problematize how online methods have been reduced to mere adaptations of previous data collection techniques and identify possible ingredients of novel online qualitative methods and techniques. They identify 
five clues for the paradigmatic development of online qualitative methods: (a) the new socialities allowed by online interactions; (b) the processes involved in asserting identities and selves online; (c) the increasing difficulty in distinguishing what is private and what is public online, and what privacy means in this context; (d) the increase of participants' agency in online qualitative research; and (e) the growing indistinction between offline and online social phenomena. The authors argue that using ontological and epistemological assumptions that do not consider the specificities of online experiences, and by focusing excessively on adapting known methods to the new settings, we are bound to conceive the online experience using offline categories, missing the opportunity to develop native, paradigmatic, online qualitative methods. We believe that this paper makes a significant contribution to the call of the special issue by promoting a new way of addressing how researchers conduct online research. It helps reframe the online/offline interface by providing guidance for researchers on how to better engage with online methods.

\section{Upcoming Issues, New Methods: Using Interactive Qualitative Analysis (IQA) in Management Research}

This paper by Behling et al. (2022) engages with a fairly new method known as interactive qualitative analysis (IQA). According to the authors, this method is a qualitative strategy to be used in management research. The IQA targets the generation of a shared mental map of focus group members on the phenomenon under study. The data collection and analysis steps are conducted in parallel, and the research participants themselves carry out the first analysis. The results are presented in a set of relationships between the elements of the shared mental map. The inductive character of the initial stages, combined with deductive procedures, allows the discovery of new ways of thinking about the investigated problems, reinforcing qualitative research's exploratory character. The replicable data collection and analysis protocol promotes reliability and validity in the research process by presenting empirical evidence. The value that IQA brings to qualitative research is that it reframes the way that research is conducted, moving from a topdown approach (researcher led) to a bottom up approach (participant led). This approach empowers participants to drive the research agenda and gives them a bigger stake in the research process and knowledge generation. We find this engagement with participants to be a meaningful and necessary contribution to qualitative research - one that might complement and parallel other existing methods such as participatory action research.

\section{Decolonial Studies, Non-Extractive Methods, and Participatory Action Research in Accounting}

This paper by Silva et al. (2022) discusses how accounting supports financial capitalism in the Global South through neocolonialist languages and practices, aiming to put forth a decolonial agenda based on non-extractive methodologies to recover alternative knowledge and (re) build new ones. The authors outline the critical accounting literature, connecting it to decolonial epistemology. They describe the assumptions behind different non-extractive methods and contrast participatory action research (PAR) with different approaches to knowledge production and consumption. In this paper, the authors engage with participatory action research (PAR) as a method for analyzing their data in the context of management and accounting studies and examine the potential for a participatory accounting agenda. According to the authors, non-extractive methods can respect and value different worldviews in each social phenomenon. This points to non-traditional and emancipatory research alternatives to produce a new 'sentipensante' in accounting to decolonize knowledge, bodies, and minds. This paper presents PAR as allowing the (re)existence of different worldviews by recognizing its ability to recover and rebuild knowledge 'with' participants. PAR supports programmatic engagement with subalternized voices to coproduce pluriversality in accounting — instead of reproducing universalisms - and bolsters academics and practitioners to transcend Western modernity. We find this paper's contribution to be significant given our view of decolonial and emancipatory research as a vital tool for addressing some of the shortfalls of research.

\section{The Qualitative Approach Interview in Administration: A Guide for Researchers}

Our final paper, by Cheron et al. (2022), returns us to what is still widely regarded as the primary research method for qualitative research in organization and management studies: the qualitative interview. The paper deliberately positions itself as a 'tutorial,' offering a step-by-step guide for considering whether, when, and how to use qualitative interviews, as well as their design and application. However, it also highlights and elaborates the intersubjectivity of interviews, and how this informs the necessary decisionmaking when using the method, such as types of interview, interview preparation, the range of possible types of question, conducting the interview, and implications for analyzing interview data. The paper also addresses questions such as asymmetry and bias, and what constitutes validity and reliability within a qualitative and intersubjective paradigm: what is required is not mechanisms for eliminating or 
controlling the biases inherent in the relationships between the subjects, but the foundation of a theory of everyday life that considers intersubjectivity. The subjects - interviewer and interviewee - weave the interview together, in a social encounter that transcends the mere transfer of information (Cheron et al., 2022). The paper therefore contributes to the special issue not only through providing a guide for researchers new to qualitative interviews, but by reasserting the claims of qualitative research to be properly considered in its own epistemological terms, and its humanistic concern for research that properly reflects and values the unique experiences, voices, and contributions of those actually involved in the phenomena we seek to investigate.

\section{FINAL THOUGHTS}

The goal of the qualitative research methods special issue is to help kick off the new qualitative methodological papers in RAC. This editorial that outlined the special issue also serves to express our thoughts on several key issues that are current challenges in conducting research in contemporary administration studies. We hope that we have created a space to engage with these pressing issues facing management studies with regard to the use of qualitative methods and methodology. Specifically, in this editorial we outlined our thoughts on the issues around generalization, reliability, and validity in the context of qualitative research, the types of question that can be engaged with in qualitative research, issues around addressing diverse voices in qualitative research, and the value that each of the papers in the special issue brings to qualitative research. We believe these issues are critical to the future of qualitative research and we hope that this editorial will serve as a call to action to question the taken-for-granted assumptions in contemporary administration research.

\section{REFERENCES}

Agee, J. (2009). Developing qualitative research questions: A reflective process. International Journal of Qualitative Studies in Education, 22(4), 431-447. https://doi.org/10.1080/09518390902736512

Behling, G., Lenzi, F. C., \& Rossetto, C. R. (2022). Upcoming issues, new methods: Using interactive qualitative analysis (IQA) in management research. Revista de Administração Contemporânea, 26(4), e200417. https://doi.org/10.1590/1982-7849rac2022200417.en

Bell, E., Warren, S., \& Schroeder, J. (2014). The visual organization. In: E. Bell, S. Warren \& J. E. Schroeder (Eds.), The Routledge companion to visual organization (pp. 1-16). London: Routledge.

Berger, R. (2015). Now I see it, now I don't: Researcher's position and reflexivity in qualitativeresearch. Qualitative Research, 15(2), 219-234. https://doi.org/10.1177/1468794112468475

Bott, E. (2010). Favourites and others: Reflexivity and the shaping of subjectivities and data in qualitative research. Qualitative Research, 10(2), 159-173. https://doi.org/10.1177/1468794109356736

Braun, V., \& Clarke, V. (2019). Reflecting on reflexive thematic analysis. Qualitative Research in Sport, Exercise and Health, 11(4), 589-597. https://doi.org/10.1080/2159676X.2019.1628806

Charmaz, K. (2006). Constructing grounded theory: A practical guide through qualitative analysis. Thousand Oaks, CA: Sage.
Cheron, C., Salvagni, J., \& Colomby, R. K. (2022). The qualitative approachinterviewinadministration:Aguideforresearchers. Revista de Administração Contemporânea, 26(4), e210011. https://doi.org/10.1590/1982-7849rac2022210011.en

Cooper,D.J., \&Sherer,M.J.(1984). Thevalueofcorporateaccounting reports: Arguments for a political economy of accounting. Accounting, Organizations and Society, 9(3-4), 207-232. https://doi.org/10.1016/0361-3682(84)90008-4

Creswell, J. (2007). Qualitative inquiry and research design: Choosing among five approaches (2 ed.). Thousand Oaks, CA: Sage.

Creswell, J. W. (2012). Qualitative inquiry and research design: Choosing among five approaches (3 ed.). Thousand Oaks, CA: Sage.

Denzin, N. K., \& Lincoln, Y. S. (2011). The Sage handbook of qualitative research. London: Sage.

Deus, E. P. de., Campos, R. D., \& Rocha. A. R. (2022). Memes as shortcut to consumer culture: A methodological approach undercovered collective ideologies. Revista de Administração Contemporânea, 26(4), e210005. https://doi.org/10.1590/1982-7849rac2022210005.en

Finlay, L. (2002). Negotiating the swamp: The opportunity and challenge of reflexivity in research practice. Qualitative Research, 2(2), 209-230. https://doi.org/10.1177/146879410200200205 
Firestone, W. A. (1993). Alternative arguments for generalizing from data as applied to qualitative research. Educational Researcher, 22(4), 16-23. https://doi.org/10.3102/0013189X022004016

Flick, U. (2018). An introduction to qualitative research. Thousand Oaks, CA: Sage.

Gabriel, Y., \& Griffiths, D. S. (2004). Stories in organizational research. In C. Cassell \& G. Symon (Eds.), Essential guide to qualitative methods in organizational research (pp. 114126). London: Sage.

Golafshani, N. (2003). Understanding reliability and validity in qualitative research. The Qualitative Report, 8(4), 597-606. https://doi.org/10.46743/2160-3715/2003.1870

Guba, E. G. (1981). Criteria for assessing the trustworthiness of naturalistic inquiries. ECTJ Educational Technology Research and Development, 29(2), 75. https://doi.org/10.1007/BF02766777

Guba, E. G., \& Lincoln, Y. S. (1989). Fourth generation evaluation. Thousand Oaks, CA: Sage.

Hamilton, J. B. (2020). Rigor in qualitative methods: An evaluation of strategies among underrepresented rural communities. Qualitative Health Research, 30(2), 196204. https://doi.org/10.1177/1049732319860267

Holstein, J. A., \& Gubrium, J. F. (2011). Animating interview narratives. In D. Silverman (Ed.), Qualitative research: Issues of theory, method and practice (3 ed., pp.149-167). Thousand Oaks, CA: Sage.

Janesick, V. (2000). The choreography of qualitative research design: Minuets, improvisations, and crystallization. In N. K. Denzin \& Y. S. Lincoln (Eds.), Handbook of qualitative research (2 ed., Chap. 13, pp. 379-399). Thousand Oaks, CA: Sage.

Kirk, J., \& Miller, M. L. (1986). Reliability and validity in qualitative research (Vol. 1). Thousand Oaks, CA: Sage. https://doi.org/10.4135/9781412985659

Lanka, S. V., Khadaroo, I., \& Böhm, S. (2017). Agroecology accounting: Biodiversity and sustainable livelihoods from the margins. Accounting, Auditing of Accountability Journal, 30(7), 1592-1613. https://doi.org/10.1108/AAAJ-12-2015-2363

Lanka, E., Lanka, S., Rostron, A., \& Singh, P. (2019). Research methods in qualitative management research. Zenodo. https://doi.org/10.5281/zenodo.3934265

Lanka, E., Lanka, S., Rostron, A., \& Singh, P. (2021). Why we need qualitative research in management studies. Revista de Administraçâo Contemporânea, 25(2), e200297. https://doi.org/10.1590/1982-7849rac2021200297.en

Lanka, E., Topakas, A., \& Patterson, M. (2020). Becoming a leader: Catalysts and barriers to leader identity construction. European Journal of Work and Organizational Psychology, 29(3), 377-390. https://doi.org/10.1080/1359432X.2019.1706488

Macbeth, D. (2001). On "reflexivity" in qualitative research: Two readings, and a third. Qualitative Inquiry, 7(1), 35-68. https://doi.org/10.1177/107780040100700103
Marshall, C., \& Rossman, G. B. (2014). Designing qualitative research. Thousand Oaks, CA: Sage.

Mauthner,N.S., \&Doucet,A.(2003). Reflexiveaccountsandaccounts of reflexivity in qualitative data analysis. Sociology, 37(3), 413-431. https://doi.org/10.1177/00380385030373002

Maxwell, J. (1992). Understanding and validity in qualitative research. Harvard Educational Review, 62(3), 279-301. https://doi.org/10.17763/haer.62.3.8323320856251826

Maxwell, J. A. (2012). Qualitative research design: An interactive approach (3 ed.). Thousand Oaks, CA: Sage.

Maxwell, J. A. (2021). Why qualitative methods are necessary for generalization. Qualitative Psychology, 8(1), 111-118. https://doi.org/10.1037/qup0000173

Melo, N. C. M., \& Dourado, D. C. P. (2022). Clues for the paradigmatic development of online qualitative methods. Revista de Administração Contemporânea, 26(4), e210015. https://doi.org/10.1590/1982-7849rac2022210015.en

Richards, L. (2005). Handling qualitative data: A practical guide. Thousand Oaks, CA: Sage.

Riessman, C. K. (2008). Narrative methods for the human sciences. Thousand Oaks, CA: Sage.

Schmuckler, M. A. (2001). What is ecological validity? A dimensional analysis. Infancy, 2(4), 419-436. https://doi.org/10.1207/S15327078IN0204 02

Shaw, R. (2010). Embedding reflexivitywithin experiential qualitative psychology. Qualitative Research in Psychology, 7(3), 233243. https://doi.org/10.1080/14780880802699092

Sikka, P., Wearing, R. T., \& Nayak, A. (1999). No accounting for exploitation. Basildon, England: Association for Accountancy \& Business Affairs.

Silva, C. M., Sauerbronn, F. F., \& Thiollent, M. (2022). Decolonial studies, non-extractive methods, and participatory action research in Accounting. Revista de Administração Contemporânea, 26(4), e210014. https://doi.org/10.1590/1982-7849rac2022210014.en

Silverman, D. (2006). Interpreting qualitative data. London, UK: Sage.

Skeggs, B. (2002). Techniques for telling the reflexive self. In T. May (Ed.), Qualitative research in action (pp. 350-374). Thousand Oaks, CA: Sage.

Strauss, A. L. (1987). Qualitative analysis for social scientists. Cambridge, UK: Cambridge University Press.

Stringer, E. (2007). Action research (3 ed.). Thousand Oaks, CA: Sage.

Van Manen, M. (1997). Researching lived experience (2 ed.). London, ON, Canada: The Althouse Press.

Varpio, L., O’Brien, B., Rees, C. E., Monrouxe, L., Ajjawi, R., \& Paradis, E. (2021). The applicability of generalisability and bias to health professions education's research. Medical Education, 55(2), 167-173. https://doi.org/10.1111/medu.14348 
Watson, T. J. (1998). The labour of division: The manager as 'self' and 'other.' The Sociological Review, 45(1_suppl), 139-154. https://doi.org/10.1111/j.1467-954X.1997.tb03458.x

Watt, D. (2007). On becoming a qualitative researcher: The value of reflexivity. The Qualitative Report, 12(1), 82-101. https://doi.org/10.46743/2160-3715/2007.1645

\section{Authorship}

\section{Evelyn Lanka*}

Cranfield University, Cranfield School of Management

College Rd, Cranfield, Wharley End, Bedford MK43 0AL, United Kingdom.

E-mail: Lyn.Lanka@cranfield.ac.uk

(D) https://orcid.org/0000-0003-0674-9955

\section{Ali Rostron}

University of Liverpool

Liverpool L69 3BX, United Kingdom.

E-mail: a.rostron@liverpool.ac.uk

(D) https://orcid.org/0000-0003-1803-720X

\section{Pallavi Singh}

Sheffield Hallam University

City Campus, Howard Street, Sheffield, S1 1WB, United Kingdom.

E-mail: p.singh@shu.ac.uk

(D) https://orcid.org/0000-0002-1933-5236

\section{Sanjay Lanka}

Fundação Getulio Vargas, Escola de Administração de Empresas de São Paulo

Rua Itapeva, 474, 01332-000, São Paulo, SP, Brazil.

E-mail: sanjay.lanka@fgv.br

(D) https://orcid.org/0000-0003-0045-1971

* Corresponding Author

\section{Conflict of Interest}

The authors have stated that there is no conflict of interest.

\section{Copyrights}

RAC owns the copyright to this content.

\section{Plagiarism Check}

The RAC maintains the practice of submitting all documents approved for publication to the plagiarism check, using specific tools, e.g.: iThenticate..
Willmott, H., Puxty, T., \& Sikka, P. (1993). Losing one's reason: On the integrity of accounting academics. Accounting, Auditing \& Accountability Journal, 6(2). https://doi.org/10.1108/09513579310036404

Yilmaz, K. (2013). Comparison of quantitative and qualitative research traditions: Epistemological, theoretical, and methodological differences. European Journal of Education, 48(2), 311-325. https://doi.org/10.1111/ejed.12014

\section{SCIENTIFIC EDITORIAL BOARD AND EDITORIAL TEAM FOR THIS ISSUE:}

\section{Editorial Council}

Alketa Peci (EBAPE/FGV, Rio de Janeiro, RJ, Brazil)

Gabrielle Durepos (Mount Saint Vincent University, Halifax, Nova Scotia, Canada)

Rafael Alcadipani da Silveira (EAESP/FGV, São Paulo, SP, Brazil)

Rafael Barreiros Porto (UnB, Brasília, DF, Brazil)

Silvia Gherardi (University of Trento, Trento, Italy)

\section{Editor-in-chief}

Marcelo de Souza Bispo (UFPB, João Pessoa, PB, Brazil)

\section{Associate Editors}

Ariston Azevedo (UFRGS, Porto Alegre, RS, Brazil)

Carolina Andion (UDESC, Florianópolis, SC, Brazil)

Denize Grzybovski (UPF, Passo Fundo, RS, Brazil)

Eduardo da Silva Flores (FEA/USP, São Paulo, SP, Brazil)

Elisa Yoshie Ichikawa (UEM, Maringá, PR, Brazil)

Emílio José M. Arruda Filho (UNAMA, Belém, PA, Brazil)

Evelyn Lanka (Cranfield School of Management, Bedford, United Kingdom)

Fernando Luiz Emerenciano Viana (Unifor, Fortaleza, CE, Brazil) Gaylord George Candler (University of North Florida, Jacksonville, Florida, USA)

Gustavo da Silva Motta (UFF, Niterói, RJ, Brazil)

Keysa Manuela Cunha de Mascena (Unifor, Fortaleza, CE, Brazil) Ludmila de Vasconcelos Machado Guimarães (CEFET-MG, Belo Horizonte, MG, Brazil)

Natália Rese (UFPR, Curitiba, PR, Brazil)

Orleans Silva Martins (UFPB, João Pessoa, PB, Brazil)

Pablo Isla Madariaga (Universidad Técnica Federico Santa María, Chile)

Paula Castro Pires de Souza Chimenti (UFRJ/Coppead, Rio de Janeiro, Brazil)

Rafael Chiuzi (University of Toronto Mississauga, Mississauga, ON, Canada)

Sidnei Vieira Marinho (Univali, São José, SC, Brazil)

\section{Scientific Editorial Board}

André Luiz Maranhão de Souza-Leão (UFPE, Recife, CE, Brazil) Aureliano Angel Bressan (CEPEAD/UFMG, Belo Horizonte, MG, Brazil) 
Bryan Husted (York University, Canada)

Carlos M. Rodriguez (Delaware State University, USA)

Cristiana Cerqueira Leal (Universidade do Minho, Portugal)

Diógenes de Souza Bido (Mackenzie, São Paulo, SP, Brazil)

Erica Piros Kovacs (Kelley School of Business/Indiana University, USA)

Elin Merethe Oftedal (University of Stavanger, Norway)

Fábio Frezatti (FEA/USP, São Paulo, SP, Brazil)

Felipe Monteiro (INSEAD Business School, USA)

Howard J. Rush (University of Brighton, United Kingdom)

James Robert Moon Junior (Georgia Institute of Technology, USA)

John L. Campbell (University of Georgia, USA)

José Antônio Puppim de Oliveira (United Nations University, Yokohama, Japan)

Julián Cárdenas (Freie Universität, Berlin, Germany)

Lucas A. B. de Campos Barros (FEA/USP, São Paulo, SP, Brazil)

Luciano Rossoni (UniGranRio, Rio de Janeiro, RJ, Brazil)

M. Philippe Protin (Université Grenoble Alpes, France)

Paulo Estevaao Cruvinel (Embrapa Instrumentação, São Carlos, SP, Brazil)

Rodrigo Bandeira de Mello (Merrimack College, USA)
Rodrigo Verdi (MIT Massachusetts Institute of Technology, Cambridge, USA)

Valter Afonso Vieira (UEM, Maringá, PR, Brazil)

Wagner A. Kamakura (Jones Graduate School of Business, Rice University, Houston, USA)

\section{Editing}

Typesetting and normalization to APA standards: Kler Godoy (ANPAD, Maringá, Brazil); Simone L. L. Rafael (ANPAD, Maringá, Brazil).

Frequency: Continuous publication.

Circulation: Free open access to the full text.

Indexing, Directories and Rankings

Scielo, Redalyc, DOAI, Latindex, Cengage/GALE, Econpapers,

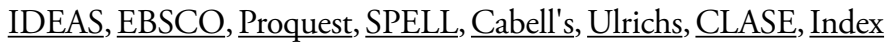
Copernicus International, Sherpa Romeo, Carhus Plust, Academic Journal Guide (ABS), DIADORIM, REDIB, Sumários.org, ERIHPlus, OAJI, EZB, OasisBR, IBZ Online, WorldWideScience, Google Scholar, Citefactor.org, MIAR, Capes/Qualis.

RAC is a member of, and subscribes to the principles of the Committee on Publication Ethics (COPE) for scholarly publication 